https://doi.org/10.48009/1_iis_2006_210-215

\title{
MEETING DYNAMIC IS MARKET DEMANDS: LEVERAGING CONSULTING PRACTICES TO GUIDE CURRICULUM REFORM
}

\author{
Sean T. McGann, Ohio University, mcgann@ohio.edu \\ Raymond D. Frost, Ohio University, frostr@ohio.edu \\ Vic Matta, Ohio University, matta@ohio.edu
}

\begin{abstract}
The dot com bust and fears of outsourcing have lead to declining IS enrollments nationwide. IS faculty have not been successful at adapting their curricula to changing market pressures. We maintain that it requires a different skill set to adapt to market forces. When businesses are not able to adapt, they often bring in consultants. Consultants typically employ a methodology to change the business while ensuring buy in and success. We were fortunate to have consultants on our staff that leveraged a change methodology to guide us through the curriculum reform process. This paper presents an account of that process and lessons learned from it.
\end{abstract}

Keywords: Information Systems Curriculum Model, IS Pedagogy, Integrated Curriculum

\section{INTRODUCTION}

In times of cyclical decline there are always some businesses that creatively reshape themselves to be successful. Southwest Airlines is a prime example in the airline industry. By relentless pursuit of customer satisfaction, they were profitable while other airlines filed bankruptcy. [3]. Similarly, this is the story of an IS department whose enrollments dropped by $65 \%$ over two years in the wake of the dot com bust and outsourcing. However, like many successful businesses facing turbulent change, we analyzed and adapted. We are now in the enviable position of increasing enrollments-75\% since 2003.

\section{The Standard Responses}

In conversations with our peers, we have noticed two standard solutions to declining enrollments. The first is to create a fifth-year master's program, as the lure of the master's helps pull students into the undergraduate pipeline. However, this requires extensive resources if the master's courses are to be more than repackaged undergraduate courses. The second response is to appeal to a wider, non-business audience through service, certificate courses, or minors offered to students in other disciplines. This helps fill classes at the low end of the curriculum but still leaves low IS core enrollments in the senior level courses of the major. Although arguably effective on some level, neither response recognizes that there are internal, department-level issues with the undergraduate IS major. In our conversations with peer institutions, we found that the problem is often labeled as being driven by external market forces beyond departmental control. This is an assumption that we challenge. By contrast, our department has looked internally to resolve its issues. Our team has completely revamped the major to make it attractive to our students and to make our students appealing job candidates. Elsewhere we have written about the outcomes of this revamp. However, in this paper we focus on the process that got us there, as it was vital to achieving our curricular goals. It is our hope that sharing this process and our lessons learned with other IS colleagues will help them attain similar goals.

\section{Diagnosing the Problem}

Driven by the symptom of significantly decreasing enrollment, we decided the first step in diagnosing the related problem was to conduct qualitative research involving all key stakeholders (i.e., students, faculty, employers and advisors). Our research showed that the IS department did not have a central strategic focus or model for its IS curriculum. Curricular decisions were made and changed in an unstructured fashion. We found that we try to teach our students not to design systems haphazardly, and yet somewhat hypocritically, we were navigating change to the curricular system in just this fashion.

By contrast, as we progressed through our process, we adopted a consulting methodology (see Figure 1 below) as a guide, which created a structured process for our curriculum revamp. This strategic methodology, presented below, guided the creation and continuous improvement of our SDLC curriculum model and the content of individual courses. It also promoted integration across courses. We adopted concepts from previous research on integrated curricula $[6,7]$ to define integration as the process of assuring that 1) all courses leverage a common framework, 2) later courses are consistent in 
their emphasis on skills, tools and deliverables taught in pre-requisite courses, and 3) pre-requisite courses build foundational skills, which will be used in later courses.

In the account that follows, we describe the process we followed, the pitfalls, and the payoff. We created an overhaul process which is replicable, and can therefore be used by other IS departments to make similar changes.

The remainder of the paper is structured as follows. Section II is a literature review of IS curriculum models. Section III describes the overhaul process. We divide the process into phases and describe what occurred in each phase. Section IV offers discussion on the process, overall lessons learned, and concluding remarks.

\section{LITERATURE REVIEW}

As discussed, we used an empirical approach to diagnosing the problem of decreasing enrollment and meeting the demands of the dynamic market. A review of the literature on curricular models in IS corroborated the changes we wanted to bring into our IS curriculum.

We began this review by examining the IS 2002 report, which is the latest output of the model curriculum work for information systems that began in the early 1970s [2]. It is the basis for accreditation of undergraduate programs of information systems. The IS 2002 model curriculum represents the views of organizations employing the graduates and is supported by other interested organizations [4]. It identified the following four main characteristics of the IS profession: a broad business and real world perspective, strong analytical and critical thinking skills, interpersonal communication and strong ethical principles, and the ability to design and implement information technology solutions that enhance organizational performance. This model posits that these characteristics are necessary to prepare students for the real world where they will need to demonstrate effective communication skills when working with clients, solving problems creatively, and working within teams [8]. The characteristics described above were resounded by our curricular reform.

However, the IS 2002 model, as well as the previous model curricula, did not specifically address issues such as what essential links and relationships exist between the suggested courses and how to integrate those courses (e.g., the ten courses in the 2002 model curriculum) so that IS students can be trained to solve practical and real IS problems in organizations. Further, a review of IS 2006 [4], the latest IS curriculum model due to be released in early 2006, still does not address this issue. Although the model does have a course referred to as the "Integrated Capstone," its concentration is on concept assimilation within that single course and not across the entire curriculum, which was a critically inherent characteristic of our objective. We did not find any research on integration across the IS curriculum.

\section{THE IS CURRICULUM OVERHAUL PROCESS}

In this section, we detail the process used to overhaul our IS curriculum. We break the process down by phases, highlighting what occurred in each phase.

\section{Phase I - Preliminary Research (9/2003-12/2003)}

We initiated a preliminary research project, which pointed to a host of structural problems in the curriculum. Evidence accumulated from our stakeholders: students (interviews and course evaluations), alumni (surveys and interviews), the IS advisory board (biannual meetings), and faculty.

The research process consisted of roughly 30 formal and informal interviews. We also looked at IS career competency and system development models from top corporate and consulting organizations.

Qualitative analysis on this data suggested a number of themes deserving attention. However, the major theme was the importance of integration and consistency across the curriculum. The advisory board was particularly clear on this point. We found that our curriculum had many of the fundamental building blocks, but no central model to tie them together. We found that this was limiting our competitive advantage to place students in the marketplace. We therefore constructed the system development lifecycle (SDLC) model to provide this grounding.

\section{Phase II - Establish The Process (9/2003)}

Armed with the knowledge that change was necessary, we next adopted a change process. Here we relied on a model derived from Andersen's consulting practice as shown in Figure 1 [1]. 


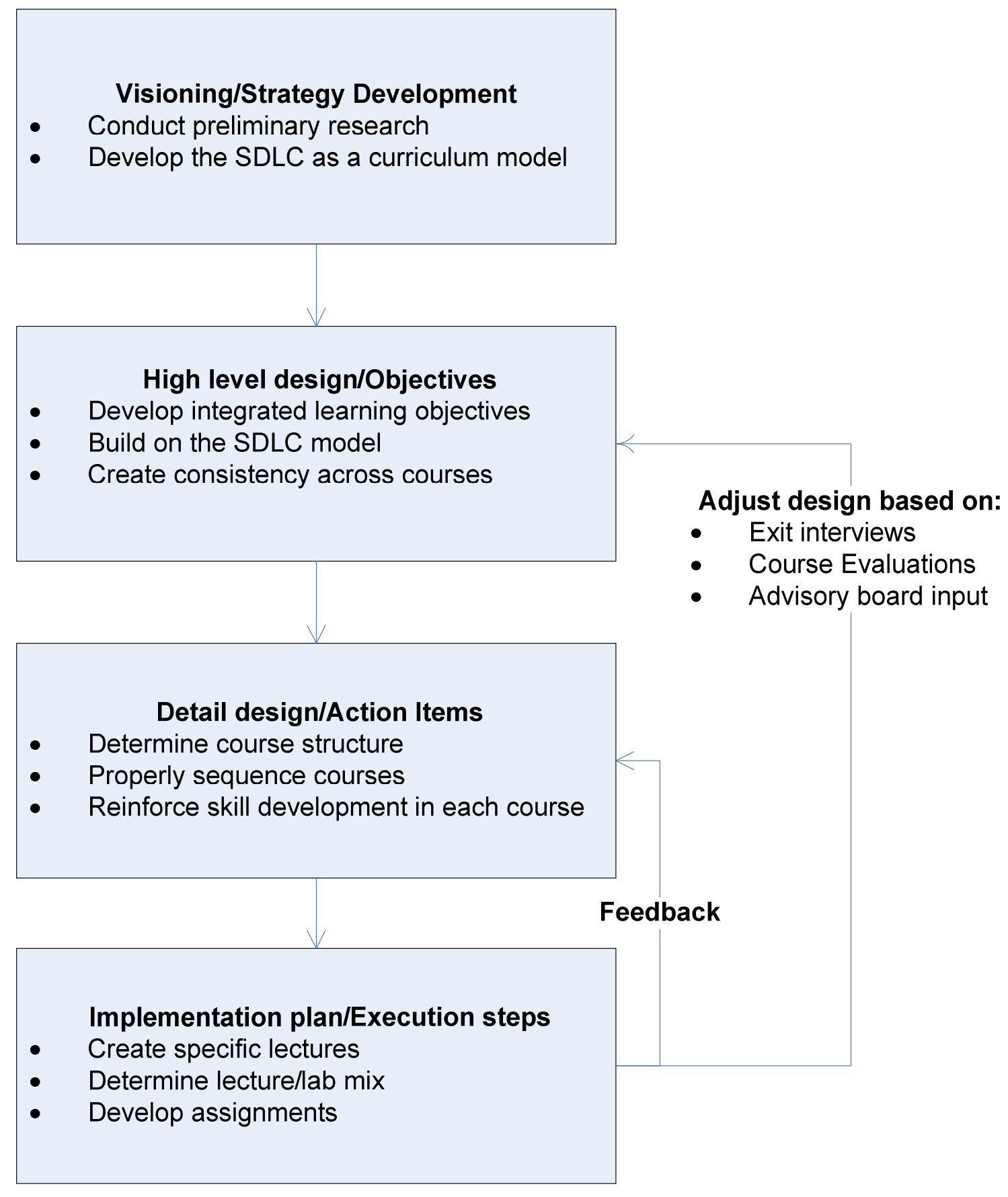

Figure 1. The Consulting Model Applied to Curriculum Reform

Figure 1 shows a sequential consulting process with a feedback loop. The four major phases are as follows: visioning, high-level design, detail design, and implementation. The bullets show the activities that took place in each phase.
The specific shared vision we adopted is not the focus of this paper, and we have written about it elsewhere. Its major tenet is that the entire curriculum would be based on developing systems leveraging the SDLC model and the key focus would be on development and integration of courses around this theme. 
From a process standpoint, there were several lessons to learn during this phase:

1. Faculty must commit to a weekly meeting to avoid starting over each time.

2. The discussion must remain at a strategic level without slipping into "quick fix" mode.

3. A moderator with consulting experience is key to keep the discussion strategic.

\section{Phase III - Building The Curriculum Model (10/2003-12/2003)}

Considerable adjustment of the initial SDLC model occurred during this phase. Upon assessing each course, we added different elements to the overall model to incorporate best practices for teaching and deliverable creation.

In conjunction with this model, we also constructed a substantial guide for all SDLC projects called the MIS Handbook. (The handbook as well as other materials described here are available upon request from the authors.) This handbook defines each phase and provides guidelines for the consistent creation of deliverables during each step in the systems development process. We benchmarked the handbook against similar life cycle handbooks from industry through the guidance of our IS advisory board. In the interest of achieving consistency across the curriculum, the faculty immediately adopted the handbook across all courses. We decided the use of this guidebook would mimic the process in industry where employees are handed a life cycle handbook when they start a new job and consult it frequently throughout their tenure as IS professionals.

After settling on the SDLC model, the faculty then designed the new course sequence. Lessons learned:

1. Consensus on details of the model and associated deliverables is difficult to reach.

2. The model adopted by the department must be documented.

3. Only after the model is adopted and documented should the process of constructing individual courses begin.

\section{Phase IV - Designing and Developing Individual Courses (10/2003-Present)}

After completing the curriculum model, our process called for designing individual courses in accordance with the SDLC model. In this process, the department formed subcommittees to construct each new course. They then presented each new course to the department overhaul team for critique and approval. We began with the first course in the curriculum and moved sequentially through our course list. For subsequent courses we decided on the following:

Where possible, the same design team would develop and test the materials for each subsequent course.

All faculty and teaching assistants delivering the course would meet once a week to design future lesson plans and to analyze what needed improvement from the prior week.

\section{Phase V - Course Implementation Process (1/2004-Present)}

While in an ideal world we would develop the materials for each new course over a period of at least a year, in reality we were pressed for time. From our perspective, our enrollment problem was one which potentially threatened viability of the major and which required a rapid implementation approach. Therefore, the process for implementation called for just-in-time delivery of course materials in accordance with the following steps:

1. The design team offered a pilot section of the course.

2. The design team created and reviewed all materials internally.

3. For assignments that touched other disciplines, we created peer review materials for the course with at least two faculty members in the associated discipline (e.g., accounting, finance, marketing, management).

4. The design team pre-tested the materials with student volunteers prior to introducing them in the course.

5. Other faculty attended the new course prior to teaching it themselves.

6. The design team remained involved in the continuous improvement process even after the handoff to other faculty. In some cases, members of the design team even sat through an entire quarter of the class serving as a teaching assistant for their successor.

7. The same design team continued to overhaul the next course in the sequence in order to ensure integration across the curriculum.

Lessons learned in this phase include the following:

1. To avoid resistance, students should be given the option to opt-in to the pilot of the new course, with the expectation that they were assisting in course development. 
2. Just-in-time delivery of materials is suboptimal but doable, given a receptive audience.

3. Attending the pilot course aids subsequent delivery of the same course.

4. Having members of the design team sit in on the course after hand off helps with continuous improvement.

5. New courses have imperfections to be worked out. Be prepared to take a hit on evaluations. The department should make allowances for this in annual evaluations.

6. Preserving the same design team for a prerequisite and the follow-on course leads to consistency and better integration.

\section{DISCUSSION AND CONCLUSION}

Since the inception of this project in the fall of 2003, we made progress in the overhaul of our curriculum and movement towards our departmental goals. We continue to make progress in the revamp and continuous improvement of our courses and are enjoying the positive results. Enrollment is up nearly $60 \%$ over the same time last year and $75 \%$ from 2003. Student satisfaction, as indicated by exit interviews and course evaluations, is also showing a highly-positive trend. Student comments indicate that the increase in enrollment is strongly tied to the new curriculum initiative. As awareness of the new IS movement increases, it is now typical to hear upperclassmen comment that they wish they had the opportunity to take the newer versions of our IS courses. Employers are highly enthused about the curriculum changes and are offering positive feedback, while aggressively hiring our students. We were near $100 \%$ placement for the 2005 graduating class, up from less then $75 \%$ the year before, and $60 \%$ the year before that. Further, new relationships with a number of large businesses evolved solely on the merits of our new curriculum and its relevance to industry.

\section{Critical Success Factors}

In an effort to provide a basis for other IS departments to initiate this process, promote curriculum integration and individual course development, we cite the following critical success factors:

1. Cultivation of a culture that values teaching.

2. Rewarding of faculty that engage in change activities.

3. Extreme collegiality.

4. Use of a skilled change consultant to moderate the reform process.
5. Use of the same toolsets, technologies and deliverables across all courses to drive integration.

6. Teach SDLC theories early and repeat them throughout the curriculum.

7. Assign the same faculty member to teach corequisites to ensure consistency of materials.

8. Assign the same faculty member to teach a course and its pre-requisite. Again this helps ensure consistency of materials.

9. Break down course boundaries. Faculty can no longer afford to operate in silos. We need to find points of integration among courses.

Although we do consider this project to be a tremendous step forward for our IS department, we realize that it is an imperfect process, and that we still have a long journey ahead of us. We also acknowledge limitations in our research process. We made the conscious decision to focus more on leveraging our data to find problems quickly than on adhering tightly to the rigors of qualitative research methodologies. However, our purpose in writing this essay was not to generate research findings grounded in theory and methods, but instead to tell our story, with an emphasis on relevance instead of rigor. This story shows how we adopted a consulting mentality in reengineering our business, without the luxury of being able to take time for methodical structure. However, having done our initial firefighting and successfully stabilized our position, we have now initiated a more rigorous process of research for future studies. These studies are designed to assess the effectiveness of our curriculum innovations and understand the dynamics that occurred. The goal of this future research is to analyze how well our courses prepare students for careers in IS, from the perspective of past and present students, and peers who have not taken our IS courses as well as their employers. We also plan to examine the overhaul process and resulting organizational dynamics through the lens of change management to examine potential contributions to that research stream. From these initiatives, we hope to offer a number of contributions to pedagogical research in IS in the future.

Finally, it is important to note that at the end of the process we found that our department needed to sell the improved IS curriculum to prospective students. To this end, we have used several techniques to get the word out, including a quarterly IS day celebration featuring a professionals' panel and casual student faculty mixers. Alumni and seniors also visited intro courses to promote career opportunities. 
Not surprisingly, as we have told this story in the academic community, we have discovered a high level of interest in our approach from other schools around the world. This interest is a key reason we took the time to write this article. We realize that there are many IS colleagues in this predicament, and we think we can help. Although this article only represents a sample of our curriculum project story, we are happy to share more with any of our peers who would like our help. We invite any and all IS professors with an interest in curriculum improvement to contact us for copies of our materials, advice or to offer criticism or ideas of their own.

\section{REFERENCES}

1. Anderson Project Management, Consulting, and Process Reengineering Methodology, Arthur Anderson, LLP, 1998.

2. Davis, G. B., Gorgone, J. T., Couger, J. D., Feinstein, D. L. \& Longenecker Jr., H. E. (1997). IS '97 Model Curriculum and Guidelines for Undergraduate Degree Programs in Information Systems, ACM, New York, NY and AITP (formerly DPMA)

3. Fisher, D. (2002). Is there such a thing as nonstop growth? Forbes, 170(1).
4. Gorgone, J., Gray, P., Stohr, E. A., Wigand, R. T. \& Valacich, J. S. (2005). MSIS 2006 curriculum preview, Communications of AIS, 15(30), 544-554.

5. Gorgone, J. T., Davis, G. B., Valacich, J., Topi, H., Feinstein, D. L. \& Longenecker, H. E. J. (2002). IS 2002 model curriculum and guidelines for undergraduate degree programs in information systems, Communications of AIS. Available online at http://www.acm.org/education/is2002.pdf.

6. Hudson, J. N. \& Tonkin, A. L. (2004). Evaluating the impact of moving from discipline-based to integrated assessment, Medical Education, 38(8), 832-843

7. Maudsley, G. (2003) The limits of tutors' comfort zones with four integrated knowledge themes in a problem-based undergraduate medical curriculum (Interview study), Medical Education, 37(5), 417-423.

8. Russell, J., Russell, B. \& Tastle, W. J. (2004). Teaching soft skills in a systems development capstone course, Proceedings of Information Systems Education Conference, 21, 1-21. 